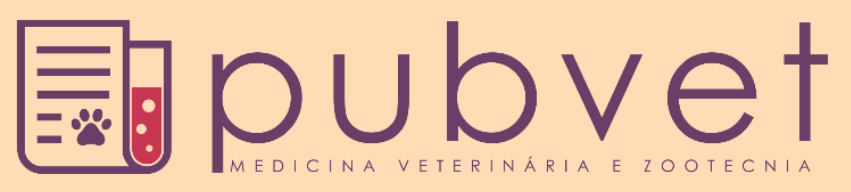

https://doi.org/10.31533/pubvet.v14n11a691.1-5

\title{
Avaliação de tratamento homeopático na prevalência da mastite bovina
}

\author{
Jordana Beal Paim ${ }^{1 *} \oplus$, Denize da Rosa Fraga ${ }^{2} \oplus$, Felipe Libardoni2 9 , Caroline Fernandes

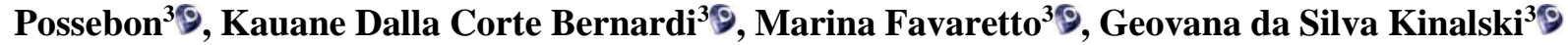

IPós Graduanda no Curso de Pós Graduação em Bovinos de Leite, Universidade Regional do Noroeste do Estado do Rio Grande do Sul (Unijuí). Ijuí, Rio Grande do Sul, Brasil.

${ }^{2}$ Médico(a) Veterinária Dr(a)., Docente da Unijuí, Departamento dos Estudos Agrários. Ijuí, Rio Grande do Sul, Brasil.

${ }^{3}$ Acadêmica de Medicina Veterinária da Unijuí, Departamento dos Estudos Agrários. Ijuí, Rio Grande do Sul, Brasil

*Autor para correspondência, E-mail: jordanabealpaim@gmail.com

Resumo. O trabalho teve como objetivo avaliar o efeito da utilização de um tratamento homeopático preventivo com o produto Masthe $\mathrm{HM}_{1000^{\circledR}}$ (Hágil terapêutica) na ocorrência de mastite subclínica em vacas leiteiras, na produção de leite e no percentual de gordura e proteína. Os dados foram coletados de duas propriedades leiteiras da região noroeste do estado do Rio Grande do Sul, os quais eram mantidos em sistema a pasto com suplementação no cocho e composto por vacas Holandesas e Jersey, sendo coletado dados de dois meses antes e dois meses após a utilização do produto homeopático. Em cima disso, pode-se concluir que a utilização da homeopatia Masthe $\mathrm{HM} 1000^{\circledR}$ (Hágil terapêutica) para mastite reduziu a ocorrência da mastite subclínica e a contagem de CCS do leite das vacas em lactação sem afetar a produção ou a composição de gordura e proteína presente no leite. A mastite é uma doença que causa grandes prejuízos no rebanho leiteiro e é um dos problemas mais frequentes nas propriedades de leite, com isso novas medidas para o controle e prevenção da mastite são um dos grandes gargalos no dia a dia do médico veterinário, sendo possível utilizar novas terapêuticas para auxiliar o produtor em frente as perdas sanitárias e financeiras que a mastite acarreta ao rebanho.

Palavras-chave: bovinos leiteiros, mastite, homeopatia

\section{Evaluation of homeopathic treatment in the prevalence of bovine mastitis}

\begin{abstract}
The objective of the study was to evaluate the effect of using a preventive homeopathic treatment with the product Masthe HM1000 ${ }^{\circledR}$ (Hágil therapeutics) on the occurrence of subclinical mastitis in dairy cows, milk production, and the percentage of fat and protein. The data were collected from two dairy farms in the northwest region of the state Rio Grande do Sul, which were kept in a pasture with supplementation in the trough and composed of Holstein and Jersey cows, the data were collected two months before and after the use of the homeopathic product. It was concluded that the use of Masthe HM1000 ${ }^{\circledR}$ homeopathy (Hile therapy) for mastitis reduced the occurrence of subclinical mastitis and the CCS count of milk from dairy cows without affecting the production or composition of fat and protein present in milk. Mastitis is a disease that causes great damage in the dairy herd and is on of the most frequent problems in the milk properties, with this new measures for the control and prevention of mastitis are one of the major bottlenecks in the veterinarian's daily routine, being possible use new therapies to assist the producer in the face of the health and financial losses that mastitis causes to the herd.
\end{abstract}

Keywords: dairy cows, mastitis, homeopathic 


\title{
Evaluación de tratamiento homeopático en la prevalencia de la mastitis bovina
}

\begin{abstract}
Resumen. El trabajo tenía como objetivo evaluar el efecto del uso de un tratamiento homeopático preventivo con el producto Masthe $\mathrm{HM}_{1000^{\circledR}}$ (Hágil terapéutica) sobre la aparición de mastitis subclínica en vacas lecheras, producción de leche y el porcentaje de grasa y proteína. Los datos se obtuvieron de dos granjas lecheras en la región noroeste del estado de Rio Grande do Sul, que se mantuvieron en pastos con suplementación en el comedero y se compusieron de vacas Holstein y Jersey, y se obtuvieron datos de dos meses antes y dos meses después del uso del producto homeopático. Además de eso, se puede concluir que el uso de la homeopatía Masthe $\mathrm{HM} 1000^{\circledR}$ (Hágil terapéutica) para la mastitis redujo la aparición de mastitis subclínica y el recuento de CCS de leche de vacas lactantes sin afectar la producción o composición de grasas y proteínas presentes en la leche. La mastitis es una enfermedad que causa grandes daños en el hato lechero y es uno de los problemas más frecuentes en las propiedades de la leche, con estas nuevas medidas para el control y prevención de la mastitis son uno de los principales cuellos de botella en la rutina diaria del veterinario, siendo posible utilizar nuevas terapias para ayudar al productor frente a las pérdidas financieras y de salud que la mastitis causa al rebaño.
\end{abstract}

Palabras clave: ganado lechero, mastitis, homeopatía

\section{Introdução}

Sabe-se que o leite está entre os produtos mais importantes da agropecuária brasileira. No ramo do agronegócio, o Brasil posiciona-se como um grande produtor mundial de leite e derivados, desempenhando papel importante no suprimento de alimentos e também na geração de emprego e renda. Porém, na pecuária leiteira, a mastite ainda é uma doença que causa grandes prejuízos econômicos, reduzindo em quantidade e qualidade o leite e os derivados lácteos (Santos, 2003). A mastite clínica caracteriza-se por alterações no leite como a presença de grumos, de fibrina ou pus e frequentemente aumento de volume, presença de dor, aumento de temperatura e rubor na glândula mamária, já a mastite subclínica caracteriza-se somente por aumento da celularidade no leite (Costa et al., 1995).

Novas medidas terapêuticas para controle e prevenção da mastite são um dos grandes desafios em rebanhos leiteiros, sendo que a terapia convencional utiliza antimicrobianos para o seu controle, porém, devido ao alto custo do tratamento e o descarte de leite a sua utilização em algumas situações é limitante (Erskine et al., 2003). Além disso, a preocupação crescente com a presença de resíduos de antibióticos no leite gera a busca de práticas alternativas para o tratamento da mastite (Costa et al., 1999), e de tentativas de busca de novas opções de tratamento menos agressivos, principalmente nos animais de interesse zootécnico, para evitar o efeito residual nos alimentos.

A homeopatia é uma possibilidade de tratamento, que se adequa, principalmente no caso das mastites. Os termos "Homeopatia" e "Homeoterapia" vêm do grego de homeo (semelhante), patia (sofrer, padecer) e therapeia (curar). A homeopatia representa uma terapia específica de estímulo do organismo, na qual a escolha do medicamento é feita de acordo com os sintomas de cada caso específico (Tiefenthaler, 1996).

Sendo assim, o objetivo deste relato é avaliar o efeito da utilização do tratamento homeopático preventivo na ocorrência de mastites subclínicas em vacas leiteiras, na produção de leite e no percentual de gordura e proteína.

\section{Material e métodos}

Dados de histórico de ocorrência de mastite subclínica, de produção e de composição do leite em relação a gordura e proteína, de dois rebanhos leiteiros na região noroeste do estado do Rio Grande do Sul, Brasil, foram comparados ao período anterior (2 meses), ao uso de produto homeopático e o período posterior (2 meses) de administração de homeopatia contra mastite, para vacas em lactação. 
As propriedades avaliadas administraram o produto homeopático Masthe HM1000 ${ }^{\circledR}$ (Hágil terapêutica) para controle da mastite em seu rebanho. Os animais da propriedade receberam 4 gramas por dia do produto, sendo duas gramas a cada turno. A ingestão se deu por via oral, misturada a ração em cocho individual (sistema de canzil).

Os rebanhos das propriedades acompanhadas mantêm sistema de produção à pasto, com suplementação dos animais no cocho, com rebanho misto, da raça Jersey e Holandesa, e mão de obra patronal. Os dados foram amostrados em períodos de entressafra de forragem, para evitar a influência da dieta sobre os dados amostrados, sendo que os rebanhos nunca receberam nenhum tipo de vacina para controle da mastite.

O Masthe $\mathrm{HM} 1000^{\circledR}$ é um medicamento homeopático utilizado para controle de mastites que tem em sua fórmula: Aerobactus complexo $21 \mathrm{CH}$; Apis mellifica $12 \mathrm{CH}$, Belladonna $12 \mathrm{CH}$, Bryonia alba $12 \mathrm{CH}$, Corinebacterium 9CH, Escherichia coli $9 \mathrm{CH}$, Phitolacca decandra $12 \mathrm{CH}$, Pulsatila nigricans $12 \mathrm{CH}$, Staphylococcinium 9CH, Satphylococcus albus 12CH, Staphylococcus aureus 9HC, Staphylcoccus complexus 12CH, Streptococcinium 12CH, Streptococccus complexus 18CH, Enterococcus sp 9CH, Klebsiella sp 9HC, Pseudomonas aeruginosa 9CH, Streptococcus agalactie 9CH e Sacarose q.s.p 400g.

Os dados de histórico de dois meses antes e após a utilização da homeopatia foram anotados em formulário específico, sendo detalhadas as seguintes características: composição do leite para gordura, proteína e contagem de células somáticas do tanque de resfriamento do leite, raça dos animais, dias em lactação, produção de leite mensal, dados referentes ao controle leiteiro individual das matrizes em lactação quanto a ocorrência de mastite subclínica, no Teste California Mastitis Test (CMT) e produção $\left(\right.$ litros $\cdot$ dia $\left.^{-1}\right)$. Apenas os dados das vacas que mantiveram a lactação nos quatro meses amostrados foram incluídos no estudo, sendo um total de 82 animais avaliados.

Após o diagnóstico de situação individual de cada propriedade, foram realizadas análises de médias dos valores para produção de leite (litros), composição do leite para gordura (\%), proteína (\%) e contagem de células somáticas (células. $\mathrm{mL}^{-1}$ ) das vacas em lactação antes e após o uso da homeopatia. Além disso, foram analisadas a frequência absoluta (n) e frequência relativa (\%) para as amostras de leite classificadas como positivas no CMT antes e após o tratamento. Procedeu-se à análise de variância e teste de comparação de médias (Teste Tukey) sendo significativos valores de $\mathrm{P}<0,10$ pelo programa $\underline{\text { SAS (2004). }}$

\section{Resultados e discussão}

Ao avaliar os dados histórico de dois meses antes e após a utilização da homeopatia, verificou-se que o rebanho era composto em média por $24 \%(\mathrm{n}=20 / 82)$ de vacas primíparas e $76 \%$ de multíparas $(62 / 82)$. A média de dias em lactação do período sem homeopatia foi de 227 dias e com homeopatia de 264 dias. $\mathrm{Na}$ Tabela 1 estão detalhados os dados de composição do leite e de volume produzido antes e após o uso da homeopatia, com base nos valores médios das vacas em lactação.

Tabela 1. Média dos valores de produção de leite, L, composição do leite para gordura, \%, proteína, \%, e contagem de células somáticas, células $\mathrm{mL}^{-1}$, das vacas em lactação antes e após o uso da homeopatia.

\begin{tabular}{lccc}
\hline Variável & Período sem homeopatia & Período com homeopatia & Valor de P \\
\hline Produção de leite (litros) & 31 & 34 & 0,5298 \\
Gordura (\%) & 3,50 & 3,79 & 0,3632 \\
Proteína (\%) & 3,29 & 3,40 & 0,5000 \\
Contagem de Células Somáticas (mil células $\mathrm{mL}^{-1}$ ) & 543 & 392 & 0,0100 \\
\hline
\end{tabular}

*Valores de $\mathrm{P}<0,10$ são significativos entre colunas.

Apesar do aumento dos dias em lactação, natural em função de avaliar os mesmos animais antes e após o uso da homeopatia, a produção de leite manteve-se e ocorreu aumento dos percentuais de gordura e proteína, com redução das contagens das células somáticas (CCS). O tratamento homeopático preventivo visa induzir uma resposta do hospedeiro capaz de inativar o microrganismo causador da mastite e assim reduzir a contagem de células somáticas. Combinações homeopáticas foram capazes de induzir redução na contagem de células somáticas de vacas leiteiras (Moncayo, 2000) e de induzir cura 
de mastite clínica em vacas (Varshney \& Naresh, 2005). Morales et al. (2005) observaram redução da CCS do leite quando administrado produto homeopático a vacas com mastite clínica por curto espaço de tempo. No entanto, alterações na gordura e proteína do leite merecem uma avaliação da dieta nos diferentes períodos, mas não se pode descartar o efeito da homeopatia sobre estes componentes do leite.

Na Tabela 2 estão descritos os dados referentes a ocorrência de mastite subclínica no rebanho. A frequências de mastite subclínica é um parâmetro consagrado na avaliação da sanidade da glândula mamária, sendo um dos primeiros a ser considerado para a implantação de um programa de controle da mastite (Fonseca, 2000). Observa-se que a utilização do produto homeopático reduziu o percentual de animais com mastite subclínica. As frequências de mastite obtidas com o uso da homeopatia situandose abaixo do valor considerado como ideal que é de 15\%, para mastite subclínica em animais (Fonseca, $\underline{2000})$.

Tabela 2. Frequência absoluta, n., e frequência relativa, \%, para as amostras de leite classificadas como positivas no CMT antes e após o tratamento com homeopatia.

\begin{tabular}{lcc}
\hline Variável & Período sem homeopatia & Período com homeopatia \\
\hline Frequência absoluta (n.) & 17 & 9 \\
Frequência relativa (\%) & $21 \%$ & $11 \%$
\end{tabular}

Assim, a avaliação de cura específica para agentes deve ser abordada com cautela, pois a homeopatia não atua em agentes microbianos em particular, mas sim em indivíduos como um todo, de forma que os reflexos dos desequilíbrios, apresentados como doença, se processem em todo o organismo, podendo as reações ser variadas com os indivíduos (Castro, 1999). Ao avaliar a taxa de cura observada de quartos mamários tratados, esta não é $100 \%$, porém deve-se considerar o custo benefício deste tratamento, uma vez que se fossem utilizados antibióticos teríamos altos custos com descarte do leite, além do risco dos animais apresentarem resíduos de antibiótico no leite, o que é um problema de saúde pública e um problema tecnológico em toda a cadeia leiteira.

\section{Conclusão}

A utilização de produto homeopático para mastite reduziu a ocorrência de mastite subclínica e contagem de células somáticas do leite de vacas em lactação, sem afetar a produção ou a composição de gordura e proteína do leite.

\section{Referências bibliográficas}

Castro, M. (1999). Homeopathy A theoretical framework and clinical application. Journal of NurseMidwifery, 44(3), 280-290. https://doi.org/10.1016/S0091-2182(99)00040-3

Costa, E. O., Carciofi, A. C., Benites, N. R., Melville, P. A., Pardo, R. B., Ribeiro, A. R., \& Watanabe, E. T. (1995). Estudo etiológico da mastite clínica bovina. Revista Brasileira de Medicina Veterinária, 17(4), 156-158.

Costa, E. O., Raia, R. B., Garino Jr, F., Watanabe, E. T., Ribeiro, A. R., \& Groff, M. R. (1999). Presença de resíduos de antibióticos no leite de pequena mistura de propriedades leiteiras. NAPGAMA, 2, 10 13.

Erskine, R. J., Wagner, S., \& DeGraves, F. J. (2003). Mastitis therapy and pharmacology. The Veterinary Clinics of North America. Food Animal Practice, 19(1), 109-38, vi. https://doi.org/10.1016/s07490720(02)00067-1

Fonseca, L. F. L. (2000). Qualidade do leite e controle de mastite (1st ed., Vol. 1). Lemos Editorial.

Moncayo. F. (2000). Efficacy of homeopathic preparations of autogenous mastitis causing organisms in the prevention of mastitis in dairy cattle. Part II: effect of an autogenous nosode on the somatic cell count of lactating cows. Organic Farming Research Foundation, 99, 4-7

Morales, R. V., Menéndez, C. C., Pasos, F. L., Quiñones, R. N., \& Cosío, E. C. (2005). Efecto de la aplicación del Reylac sobre la calidad de la leche en rebaños con mastitis subclinica bovina. REDVET. Revista Electrónica de Veterinaria, 6(6), 1-7.

Santos, M. V. (2003). Impacto econômico da mastite bovina. Hora Veterinária, 22(131), 46-50. 
SAS. (2004). SAS/STAT User guide, Version 9.1.2. SAS Institute Inc.

Tiefenthaler, A. (1996). Homeopatia para animais domésticos e de produção. In Homeopatia para animais domésticos e de produção (p. 336).

Varshney, J. P., \& Naresh, R. (2005). Comparative efficacy of homeopathic and allopathic systems of medicine in the management of clinical mastitis of Indian dairy cows. Homeopathy, 94(2), 81-85.

Recebido: 24 de julho, 2020

Aprovado: 3 de setembro, 2020

Disponível online: 23 de outubro, 2020
Licenciamento: Este artigo é publicado na modalidade Acesso Aberto sob a licença Creative Commons Atribuição 4.0 (CC-BY 4.0), a qual permite uso irrestrito, distribuição, reprodução em qualquer meio, desde que o autor e a fonte sejam devidamente creditados. 